\title{
Emulsion and Lyophilisate for Suspension for Injection Dosage Form
}

National Cancer Institute

\section{Source}

National Cancer Institute. Emulsion and Lyophilisate for Suspension for Injection Dosage

Form. NCl Thesaurus. Code C149476.

Sterile emulsion and sterile lyophilisate, both of which contain active substance(s),

intended for the preparation of a suspension for injection, for veterinary use, by

dispersing the lyophilisate in the emulsion. 